\title{
The B.E.S.T. model of performance enhancement
}

\author{
John A. Franklin \\ Psychology Department \\ Macquarie University \\ Sydney, Australia
}

\begin{abstract}
Research by Dweck, Bandura and others has demonstrated the central role that cognitions, behavioural and environmental factors play in achievement and wellbeing. This paper introduces the B.E.S.T. Model of Performance Enhancement, a self-reflective educational exercise derived from the Thrive and Survive Theory of motivation and performance (Franklin, 2019). B.E.S.T. represents a simple mnemonic that assists coaching clients to understand and identify the role that beliefs, environment, skills and talent play in determining their performance. A case study is provided to illustrate how the model may be employed in coaching to facilitate personal growth and performance enhancement.
\end{abstract}

Keywords: Coaching, theories, models, mindset, performance, achievement

\section{Introduction}

Coaching generally involves assisting normally well-functioning people to improve some aspect of their life situation, such as their performance, wellbeing or health. Coaching often occurs within significant constraints of time and resources, placing a premium on quickly assisting the client to understand their situation, identify solutions and work towards their successful implementation. This process can be facilitated by a coach's understanding of theories and models that help to analyse situations and can be shared with clients in a way that enables co-constructed helpful responses. Coaching is not short of candidate theories and models, but what is lacking are simple visual representations of the vital factors involved in driving human behaviour change. This paper seeks to present a possible solution to this need by drawing upon Thrive and Survive Theory (Franklin, 2019) to highlight the role that beliefs, the environment, skills and talent play in determining the performance of desired behaviour change. 
The work of Carol Dweck and associates (Dweck, 2006; 2015; Dweck \& Yeager, 2019) has focused principally on the role of ability and whether the beliefs one has about one's ability can be enhanced through effort and learning. Those with a growth mindset are said to believe that their ability (principally their intelligence) may be increased, motivating them to exert effort to learn and improve. In contrast, people with fixed mindsets tend not to hold such beliefs. Although Dweck's model essentially identifies ability and mindset as the twin drivers of performance, it also acknowledges that the social environment may influence the beliefs one holds. Dweck has expressed concern at the difficulty of accurately conveying this model to others (Dweck, 2017).

Social learning theory (SLT) identifies three primary drivers of behaviour. They include, (i) cognitive factors (including beliefs, especially selfefficacy beliefs), (ii) behavioural factors (including skill, practice), and (iii) environmental factors (including social influences; Bandura, 1977, 1982, 1997). Unlike Dweck, SLT pays little attention to the role of those aspects of talent or ability that may have a stronger biological basis (e.g. intelligence, temperament, physical functioning or state, developmental stage and genes). What is needed is a theory that integrates all of these factors into a simple to understand, remember and apply model of human behaviour change.

\section{Thrive and Survive Theory}

Thrive and Survive Theory (TST; Franklin, 2019) is an integrated theory of motivation, performance and well-being that expands on the role of mindset and incorporates a variety of others factors to explain the outcomes people desire in life. As shown in Figure 1, TST asserts that client outcomes are the result of the responses they make to challenging life events. These challenges may be in their external environment (e.g., promotion, demotion, financial insecurity, parenthood, relationship changes) or within them (e.g., emotions, cognitions, behaviours). Clients seek to reduce the possible threat or capitalise on the opportunity presented by drawing on internal or external sources of control. If their responses enable them to control the challenges such that they satisfy their needs, wants and expectations, then they produce positive outcomes such as success, health and happiness. However, if the responses do not satisfy their needs, wants or expectations then negative outcomes may result (e.g. failure, ill health and misery). As such, the theory suggests that improving life outcomes requires a focus on whatever internal and external resources enable them to manage challenges and satisfy their needs (or possibly unreasonable or unattainable wants and expectations). Enhancing or capitalising 
on these internal and external resources is thus critical to determining the effectiveness of any response made to the challenges occurring in their life.

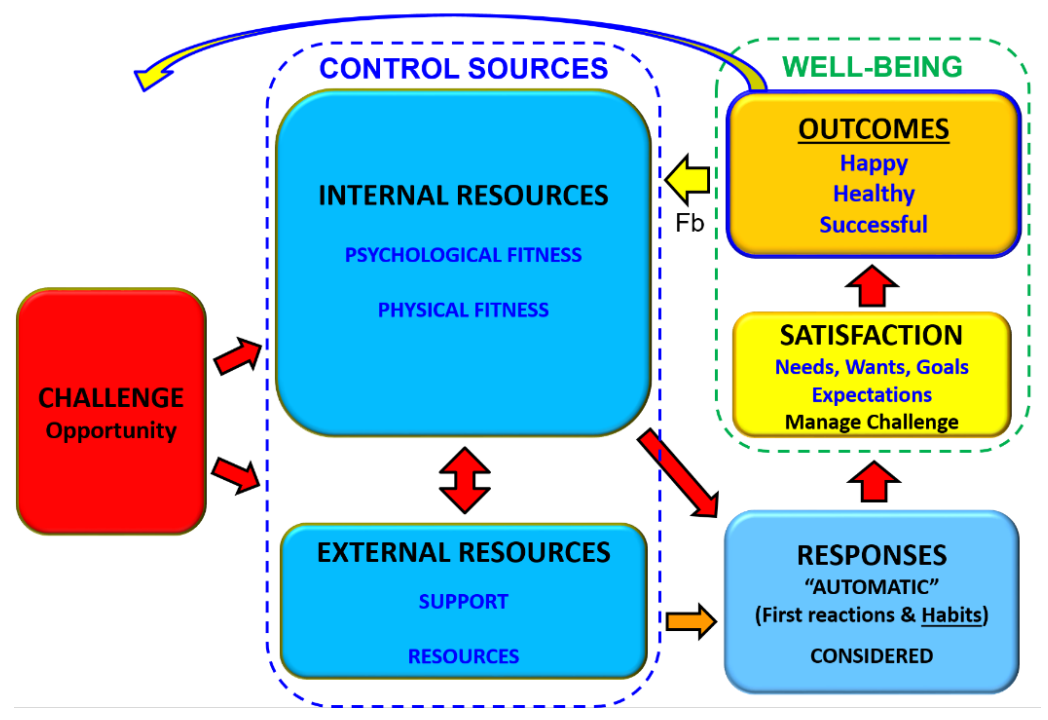

Figure 1. Thrive and Survive Theory

In TST, internal resources consist of a client's Psychological Fitness (including their beliefs, skills, knowledge and understanding) and their Physical Fitness (including their talent, abilities, developmental stage, physical state and genetic endowment). External resources include the client's social, cultural, political, economic, legal and physical environment. Coaching enables clients to draw upon and/or develop resources that permit effective responses to challenges, such that desired outcomes can be achieved in the minimum time. To do this, clients need to improve their performance (responses) in certain critical areas of their life, areas that are captured in the B.E.S.T. Model of Performance Enhancement.

\section{The B.E.S.T. Model of performance enhancement}

This model focuses on the interaction of four significant internal drivers of performance: beliefs, environment, skills and talent. As shown in Figure 2, these factors can be organized into an interactive exercise to help clients identify and remember how the various factors affect their performance and how they might need to be modified to improve performance. 


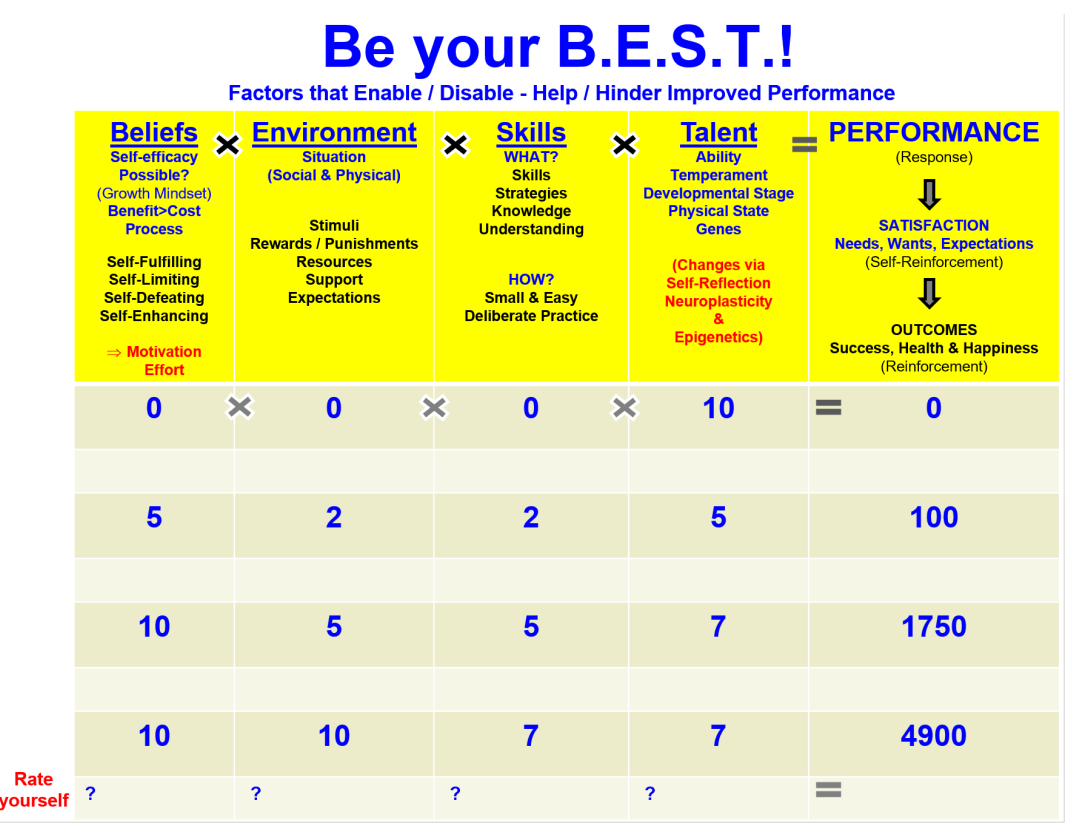

Figure 2. The B.E.S.T. Model of Performance Enhancement

When used with a client, B.E.S.T. can be helpful for identifying both challenges and desired outcomes. It serves as an educational aide by promoting self-reflection about factors that determine client performance. As mentioned above, B.E.S.T. is a simple mnemonic that identifies the importance of beliefs, environment, skills and talent. In practice, clients are asked to identify the factor(s) most significant to their performance that will help them respond to challenges and achieve their desired outcomes. Whilst some combination of ability, talent, intelligence, personality or temperament are normally identified, clients are generally challenged to name other internal or external factors that may also be important. The coach then proceeds to examine each of these factors paying particular attention to the roles played by beliefs, environment, skills and talent. Talent often proves to be insufficient to guarantee high performance and this helps draw attention to the role of other factors. The manner in which each of these four factors enable or disable performance is then examined with respect to their unique circumstances and concerns. Empirical investigation of programs using the B.E.S.T. model have shown it to be helpful for assisting students transition to university (Franklin \& Doran, 
2009; Franklin \& Franklin, 2012). Further explanation of its four components follows and their relationship to TST is discussed in Franklin (2019).

\section{Beliefs}

Whilst many beliefs can help or hinder performance, four are of particular importance. These are beliefs about; (i) their self-efficacy that they can perform as required, (ii) being able to make changes that will improve their performance, (iii) the net benefits of improving their performance, and (iv) the process by which improvement may be achieved. All of these beliefs will contribute to the motivation to change and the effort they are willing to invest to make it happen. The relationship of self-efficacy beliefs to performance is well established (Bandura, 1997). Clearly if the client does not believe it is possible to do anything to improve their situation (i.e. they have a fixed mindset) then no action will be taken. Likewise, if the perceived cost of the changes exceeds the perceived benefits then they will be unmotivated to exert effort. Finally, if the client does not appreciate the importance of their beliefs, environment, skills and talent in driving performance then they will neglect to act on these other factors. The significance of these beliefs is then examined, particularly the extent to which they are self-fulfilling, self-limiting, selfdefeating or self-enhancing. TST proposes many techniques and exercises designed to examine these beliefs, particularly establishing a realistic evaluation of the costs and benefits of action and inaction.

\section{Environment}

The role of the environment in enabling or disabling desired behaviour change is frequently underestimated. Many aspects of the environment may effect behaviour, including social, physical, work, legal, economic, cultural, religious, and family factors. Aspects of each of these environments may help or hinder desired behaviours. They may stimulate, trigger or provoke certain responses (e.g. eating, drug use, anger, exercise, use of persuasive or addictive technology), reward or punish certain actions (e.g. working late, crossing boundaries, willingness to share and co-operate), support or discourage change (e.g. mentor or partner), provide resources (e.g. access to information, materials, education, technology, finance) and expectations (e.g. belief in the client's capacity to change and perform). Examination of environmental influences will hopefully allow clients to identify how to arrange their life so as to facilitate the changes they desire. Examining critical moments of success and failure may assist in identifying environmental factors that are working for or against the client in any situation, and thus what needs to be changed. 


\section{Skills}

It is very difficult to enhance performance if clients lack the necessary skills, knowledge and understanding. As such, encouraging a skills scan will help identify which skills and strategies are required for improved performance, along with any domain-specific knowledge or expertise that might be needed (e.g. tax law, what makes for a lasting relationship). Also important is understanding what needs to change (e.g. emotional self-regulation, competence in social, study, work, writing or learning skills) and how that is best achieved (e.g. problem solving, starting small, making it easy to change, incremental improvement via deliberate practice). The skills needed to perform successfully are often very specific to the person, situation and challenge. Coaching expertise can be valuable in the identification of critical skills and knowledge and ultimately successful behaviour change. Many changes may help, but not all changes are of equal benefit. Coaching helps identify those changes that are easiest to make and which will make the biggest difference. Converting these skills into automatic habits will reduce the cognitive load and make the desired behaviours and performance easier and more reliable.

\section{Talent}

Talent refers not just to intelligence but also to a wide range of specific abilities, strengths and interests that facilitate performance and adaptation. It includes frequently overlooked qualities such as interest, kindness, consideration and the ability to connect with others. In many life situations these attributes are more highly valued and rewarded than conventional forms of intelligence like mathematical ability. Such qualities are essential to forming lasting friendships, influencing others, establishing alliances, recruiting followers and leading others. The world handsomely rewards these talents, yet they are often overlooked or undervalued. The notion of talent needs to be expanded to include those qualities which facilitate adaptive, co-operative and competitive behaviours. Talent also includes a variety of other qualities such as temperament, developmental stage, physical state and genetic endowment. Certain temperamental characteristics such as emotional reactivity may make some changes easier or harder (Kagan \& Snidman, 2004). Likewise, one's developmental stage (Kegan \& Lahey, 2009) may facilitate or inhibit change. A client's physical functioning or state (e.g. sleep debt, mental or physical fatigue, fitness, health, emotional state) will help or hinder behaviour change and may need to be the focus of change. There is now substantial evidence that the development of skills and habits induce underlying neurological changes that produce lasting changes in the brain (Costandi, 2016). Recent studies also 
suggest that changes in cognition and behaviour also produce epigenetic changes in the expression of underlying genes (Pelletier, 2019). Both of these biological processes (i.e., neuroplasticity and epigenetics) may enhance the talents which a client may draw upon to lift their performance and better cope with or exploit challenging life events.

\section{Performance}

In the B.E.S.T. model the effect of beliefs, environment, skills and talent on performance are considered multiplicative rather than additive. The reason for this can be best explained using an example. Consider the effect on performance of a complete lack of belief or skill. Even if a person were highly talented (rated 10 out of 10 for talent) the absence of motivation resulting from a lack of belief ("There is no way I can do that") or a lack of skill ("I don't have a clue about how to do this") is likely to result in non-performance of a task. As shown in Figure 2, clients can be asked to rate themselves on a $0-10$ scale $(0=$ nothing; $10=$ maximum) for each of the four areas, relative to something they would like to improve upon or achieve. Consider the situation if they had a reasonably supportive environment $(5 / 10)$, were moderately skilled $(5 / 10)$, were averagely talented $(5 / 10)$ but believed that it was useless trying to improve their performance or there was no benefit to be had $(0 / 10)$. In such a case they are likely to withhold their effort, yielding zero performance (i.e. $0 \times 5 \times 5 \times 5=0$ ). This would also be true if they had a hostile environment (0/10), had zero skills $(0 / 10)$ or had zero talent $(0 / 10$, although this would never happen as people always have some talent). Nonetheless, in any situation where one of the four factors is zero, the resulting performance would be zero. Where varying levels of belief, environment, skills and talent exist, the performance profile changes (see Figure 2). Clients report finding this visual illustration very memorable and persuasive. It also helped them understand how these changes enhanced selfefficacy beliefs and ultimately performance.

When using B.E.S.T. people are requested to apply this to their own situation by identifying some area of performance they would like to improve, then rating their talent, skills, environment and the belief that they can achieve what they desire. Examination of the numbers helps identify what changes would produce the biggest improvement in their performance. Experience has shown that most people find this to be their level of belief, which is consistent with Dweck's work on the profound motivational effects of belief (Dweck \& Yeager, 2019) and Bandura's extensive research on self-efficacy (Bandura, 1997). However, all four factors impact performance and need to be examined 
in the search for the most effective targets for change as they are likely to differ considerably between clients.

\section{Illustrative case example}

Upon seeking entry to university, a 20-year old man ("Everett") was interested in identifying changes he might need to make to be successful. Everett was referred following a failed attempt to enroll in first year university the previous year. His sense of intellectual inadequacy and fear of failure had caused him to withdraw after a few weeks and he now sought coaching in an attempt to overcome these fears and complete a degree. Applying the B.E.S.T. model helped him to see that he had very little belief in his ability to succeed academically. Coming from a disadvantaged working-class background, Everett judged his intelligence to be low, viewing others as much brighter and more able. It had never occurred to him that even if he was of only of average intelligence (and his high school results suggested otherwise) he could still do well by working on his beliefs, environment and skills. This helped him gain a more accurate understanding of what needed to change and what would raise his chances of academic success.

After examining the self-fulfilling nature of beliefs, Everett realised how his negative beliefs regarding his ability would likely be self-limiting and possibly self-defeating. Revising his views about the possibility of success would hopefully be self-enhancing. His motivation was further strengthened by having him write out the full costs to him of not going to university and the many benefits of undertaking study and achieving succeed. This was consolidated by him writing out and carrying with him a personal motivational statement which reminded him of why it was essential to his sense of self and future that he succeed at university.

Analysis of Everett's environment revealed that his home situation was not supportive of his decision to continue his education as the home was noisy and his father continually taunting him to "get a trade". He created a more supportive physical and social environment by contacting a friend who was also enrolling and agreeing to study with him away from home. With respect to skills, analysis revealed that he lacked writing and study skills so he enrolled in an academic skills program run by the university. He also came to appreciate that he lacked emotion regulation skills and a mobile app was downloaded to help him engage in regular relaxation exercises. To increase his understanding of what was expected he approached the director of each unit at the start of the semester and immediately after each lecture if he was uncertain of any of the 
lecture content. These steps greatly increased his level of self-efficacy, as did his attending a session on self-compassion and the self-defeating nature of perfectionism.

Finally, Everett sought to enhance his physical state and talent by ensuring he got sufficient sleep, ate well and undertook daily exercise. He attended six coaching sessions that systematically applied the BEST formula to identify changes which would increase his academic performance. These changes enabled him to successfully enroll at university and, ultimately graduate with Honours. He remained socially anxious but felt triumphant, particularly when he gained secure employment as an assistant magazine editor.

\section{Conclusions and Implications}

Most people wish to improve their performance in some area of their life but are held back by not understanding what changes will make this possible. The B.E.S.T. model provides a simple visual representation of the four major factors that drive performance (beliefs, environment, skills and talent). Close examination of these drivers enables people to focus on identifying those specific changes that will produce the biggest gain for the smallest change. For many these are personal beliefs, as people often seem held back by what they believe (or do not believe) they can achieve, rather than their actual ability (the level of which is ultimately unknowable). Changes in belief have a potentiating effect on motivation, the level of effort expended, the environmental changes engineered, the level of skill developed, the understanding sought, and the maximisation of their talent. Beliefs tends to be self-fulfilling and, if positive, they are self-enhancing, rather than self-limiting or self-defeating (Jussim \& Harber, 2005). The B.E.S.T. model facilitates the development of a growth mindset and from the perspective of TST, both psychological fitness and physical fitness. It is hoped that the model in conjunction with TST will assist clients to more quickly and comprehensively identify the changes that are necessary to achieve the outcomes they desire.

\section{References}

Bandura, A. (1977). Self-efficacy: Towards a unified theory of behaviour change. Psychological Review, 84(2), 191-215.

Bandura, A. (1982). The self-efficacy mechanism in human agency. American Psychologist, 37(2), 122-147.

Bandura, A. (1997). Self-Efficacy: The Exercise of Control. Freeman. 
Costandi, M. (2016). Neuroplasticity. MIT Press.

Dweck, C.S. (2006). Mindset: The New Psychology of Success. Random House.

Dweck, C.S. (2015). Growth. The British Journal of Educational Psychology. $85,242-245$

Dweck, C.S. (2017). Mindset: Changing the Way You Think to Fulfil Your Potential. Robinson.

Dweck, C.S. \& Yeager, D.S. (2019). Mindsets: A view from two eras. Perspectives On Psychological Science: A Journal of the Association For Psychological Science, 14(3), 481-496.

Franklin, J. A. (2019). Achieving success and happiness: The relevance of theories of well-being and flourishing in positive psychology coaching. In S. Green \& S. Palmer (eds.), Positive Psychology Coaching in Practice. Routledge (pp 21-39).

Franklin, J. \& Doran, J. (2009). Does all coaching enhance objective performance independently evaluate by blind assessors? The importance of the coaching model and content. International Coaching Psychology Review, 4, 126-142.

Franklin, J. \& Franklin, A. (2012). The long-term independently assessed benefits of coaching: A controlled 18-month follow-up study of two methods. International Coaching Psychology Review, 7, 33-38.

Jussim, L. \& Harber, K. D. (2005). Teacher expectations and self-fulfilling prophecies: Knows and unknowns, resolved and unresolved controversies. Personality and Social Psychology Review, 9(2), 131155 .

Kagan, J. \& Snidman, N.C. (2004). The Long Shadow of Temperament. Harvard University Press.

Kegan, R. \& Lahey, L. L. (2009). Immunity to Change: How to Overcome It and Unlock Potential in Yourself and Your Organization. Harvard Business Press.

Pelletier, K. R. (2019). Change Your Genes, Change Your Life. Origin Press 


\author{
Author Contact \\ Dr John Franklin \\ Psychology Department \\ Macquarie University \\ Sydney, NSW \\ Australia \\ E: john.franklin@mq.edu.au
}

